\title{
CORRELAÇÃO DE POLIMORFISMOS NO GENE DA GALECTINA-9 COM ATIVIDADE DA DOENÇA NA ESCLEROSE SISTÊMICA
}

\author{
K. M. VILAR ${ }^{1}$, E. G. C. CUNHA ${ }^{1}$, M. C. PEREIRA ${ }^{1}$, A. T. DANTAS ${ }^{2}$, A. L. B. P. D.
} DUARTE $^{2}$, I. R. PITTA ${ }^{3}$; M. J. B. M. REGG ${ }^{1}$ e M. G. R. PITTA ${ }^{1}$

${ }^{1}$ Universidade Federal de Pernambuco, Laboratório de Imunomodulação e Novas Abordagens Terapêuticas, Núcleo de Pesquisa em Inovação Terapêutica Suely-Galdino (Nupit-SG).

${ }^{2}$ Serviço de Reumatologia, Hospital das Clinicas, Universidade Federal de Pernambuco.

${ }^{3}$ Laboratório de Planejamento e Síntese de Fármacos, Núcleo de Pesquisa em Inovação Terapêutica Suely Galdino, Universidade Federal de Pernambuco.

E-mail para contato: kamilamelo_vilar@hotmail.com

RESUMO - A esclerose sistêmica (ES) é uma doença do tecido conjuntivo autoimune, caracterizada pela presença de fibrose. A galectina-9 (gal-9) pertence a familia das lectinas e é atualmente conhecida como um imunomodulador que afeta uma série de tipos de células. As alterações genéticas no LGALS9 podem contribuir para o agravamento e desenvolvimento de diversas doenças. Por isso a importância de identificar polimorfismos no LGALS9 que estejam relacionados à ES e correlacionar com os níveis séricos de gal-9 nos pacientes e controles. Foram coletados $4 \mathrm{ml}$ de sangue de 36 pacientes com ES no Serviço de Reumatologia do HC-UFPE, o grupo controle foi formado por 44 individuos saudáveis. Selecionamos polimorfismo o rs4795835 para analisarmos sua influência na susceptibilidade na ES. A gal-9 presente no soro dos pacientes e dos controles foram quantificadas por ELISA. O alelo $C$ apresentou uma maior frequência nos controles quando comparados aos pacientes com ES $(p=0,0059)$. Não encontramos correlações entre os genótipos e níveis séricos da gal-9 tanto nos pacientes quanto no grupo controle. No entanto, quando estratificamos os genótipos, pacientes que possuíam o alelo T apresentaram altos níveis da gal-9 no soro $(p=0,0415)$. Nossos resultados sugerem que pacientes com ES que possuíam o alelo T apresentaram elevados niveis da gal-9 no soro. Novos pacientes estão sendo avaliados para aumentar o " $n$ " e assim termos uma melhor correlação com o risco de desenvolver a doença.

Palavras chave: Galectina. Doença autoimune. Imunogenética.

ABSTRACT - Systemic sclerosis (SSc) is an autoimmune connective tissue disease, characterized by the presence of fibrosis. Galectin-9 (gal-9) belongs to the lectin family and is now known as an immunomodulator that affects a number of cell types. Genetic alterations in LGALS9 may contribute to the aggravation and development of several diseases. Therefore the importance of identifying polymorphisms in LGALS9 that are related to SSc and correlate with serum levels of gal-9 in patients and controls. Four $\mathrm{mL}$ of blood from 36 patients with SSc were 
collected at the HC-UFPE Rheumatology Service, the control group consisted of 44 healthy individuals. We selected polymorphism rs4795835 to analyze its influence on SSc susceptibility. Gal-9 present in the patients' serum and controls were quantified by ELISA. The C allele had a higher frequency in the controls when compared to the ES patients $(p=0.0059)$. We found no correlation between genotypes and serum levels of gal-9 in both patients and the control group. However, when we stratified the genotypes, patients who had the Tallele had high serum levels of gal-9 $(p=0.0415)$. Our results suggest that SSc patients who had the Tallele had elevated levels of gal-9 in serum. New patients are being evaluated to increase the " $n$ " and thus have a better correlation with the risk of developing the disease.

Keywords: Galectin. Autoimmune disease. Immunogenetics.

\section{INTRODUÇÃO}

ES é uma doença do tecido conjuntivo auto-imune, extremamente heterogênea caracterizada por vasculopatia fibroproliferativa, anormalidades imunológicas com presença de auto-anticorpos e fibrose progressiva da pele e múltiplos órgãos incluindo pulmão, rim, coração, trato gastrointestinal e pele. De acordo com a extensão e local do acometimento cutâneo, a ES pode ser classificada clinicamente em: cutânea limitada (CL) e cutânea difusa (CD) (DESBOIS et.al., 2016).

As galectinas são lectinas que se ligam a $\beta$-galactose com uma alta afinidade por $\beta$-galactose em glicoconjugados e participam de uma diversidade de mecanismos celulares contribuindo para respostas imunes inatas e adaptativas, fundamentais para patogênese das doenças auto-imunes (NIO-KOBAYASHI et.al., 2017).

A galectina-9 (gal-9) é atualmente conhecida como um imunomodulador versátil que afeta uma série de tipos de células.Pertencente à família das galectinas de repetições em tandem, formada por dois domínios de ligação à carboidratos conectados por um domínio de ligação com comprimento variável Em humanos, os genes codificados por um braço mais longo do cromossomo 17, são chamados LGALS9 (HEUSSCHEN et al., 2013).

As alterações genéticas no LGALS9 podem contribuir para o agravamento e desenvolvimento de diversas doenças. Por isso a importância de identificar polimorfismos no $L G A L S 9$ que estejam relacionados a esclerose sistêmica e correlacionar os genótipos com os níveis séricos de gal-9 nos pacientes e controles.

\section{MATERIAIS E MÉTODOS}

Foram coletados $4 \mathrm{ml}$ de sangue periférico, no Serviço de Reumatologia do HCUFPE, 36 paciente com diagnostico de ES,e o grupo controle foi formado por 44 pacientes voluntários. O material coletado foi encaminhado ao Laboratório de Imunomodulação e Novas Abordagens Terapêuticas (LINAT). O DNA da amostra foi extraído utilizando a técnica de extração "In House". Os polimorfismos foram selecionados através do site: http://hapmap.ncbi.nlm.nih.gov/, levando em consideração a freqüência do Alelo Menor (MAF) maior que 0,1 na população europeana (CEU). Selecionamos o SNPs rs4795835 para analisarmos sua influência na susceptibilidade na 
ES. A reação de PCR foi realizada utilizando o termociclador StepOnePlus ${ }^{\mathrm{TM}}$ Real-Time PCR System (Applied Biosystem). A galectina-9 presente no soro dos pacientes e dos controles saudáveis foram quantificadas por ELISA sanduíche, tendo como limite de detecção $46.87 \mathrm{pg} / \mathrm{ml}$,seguindo as informações recomendadas pelo fabricante (R\&D Systems). A análise da genotipagem foi do tipo caso-controle, o teste estatístico utilizado foi o qui-quadrado $\left(\mathrm{X}^{2}\right)$. Foi utilizado o teste $\mathrm{t}$ não paramétrico de Mann-Whitney, e os valores de $\mathrm{p}>0,05$ foram considerados significativos.Para avaliar o equilíbrio de HardyWeinberg (HW) utilizamos o site: http://oege.org/software/hardy-weinberg.html

\section{RESULTADOS E DISCUSSÃO}

Foram analisados 36 pacientes com ES e 44 controles, com a média de idade de 25.1 e 23.16 respectivamente, como demonstrados na tabela 1.

Tabela 1 - Dados grupo controle e pacientes com ES.

\begin{tabular}{ll}
\hline Controles & $\mathrm{N}=44$ \\
Homem/Mulher & $4 / 40$ \\
Média de idade & $25.1(20-78)$ \\
ES & $\mathrm{N}=36$ \\
Homem/Mulher & $1 / 35$ \\
Média de idade & $23.16(20-79)$ \\
\hline
\end{tabular}

Os resultados que obtivemos das análises foi do tipo caso-controle, avaliando se os portadores de ES e o grupo controle estavam no equilíbrio de HW. O rs4794976 apresentou um $p<0,05$, estando no equilíbrio de HW. O teste $X^{2}$ foi realizado para avaliar as correlações caso-controle com os polimorfismos e encontramos para o rs um Odds_ratio $(\mathrm{OR})=0,3960$, chi2 $=0,0046, p=0,0059$ para o alelo C. Em relação a frequiência dos genótipos, encontramos o alelo $\mathrm{C}$ mais frequente nos controles quando comparados aos pacientes com ES, como demonstrado na figura 1a. Não encontramos correlações entre os genótipos e os níveis séricos da gal-9 tanto nos pacientes quanto no grupo controle. No entanto, pacientes que apresentaram o alelo $\mathrm{T}$ apresentaram altos níveis da galectina 9 no soro $(\mathrm{p}=0,0415)$. Figura $1 b$.

Figura 1- (a) Frequência dos alelos no grupo controles e pacientes com ES. (b) Correlação dos níveis séricos da galectina 9 com os genótipos do rs4794976 nos pacientes com ES.

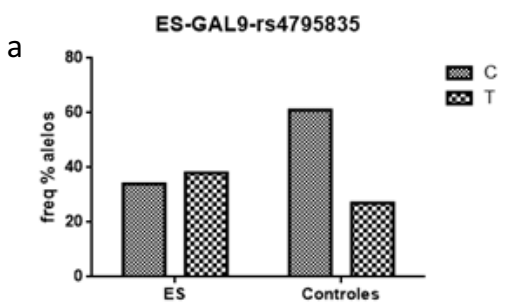

b



\section{CONCLUSÃO}


Nossos resultados mostram que pacientes com ES, que possuíam o alelo $\mathrm{T}$ do rs4794976 apresentaram elevados níveis da gal-9 no soro ( $p=0,0415)$, enquanto o alelo $\mathrm{C}$ apresentou uma maior frequência nos controles quando comparados aos pacientes com ES (0,0059). Por ser uma galectina responsável pela indução do desequilíbrio imunológico, sua atividade na esclerose pode estar relacionada com o escore da pele desses pacientes. Novos pacientes estão sendo avaliados para aumentar o "n" dos casos e assim termos uma melhor inferência das correlações com o risco de desenvolver a doença.

\section{REFERÊNCIAS}

H, R., G, AW., Thijssen VL.(2013) Galectin-9 in tumor biology: a jack of multiple trades. Biochim Biophys Acta.;1836(1):177-85.

H, AM., M, EN., C, MR., T, F., R, MC., K, LB.,L, EP., F, LT., M, FK., R, RM., M, NP., C, FM., F, TP., O, RA., C, IP. Incidence and prevalence of systemic sclerosis in Campo Grande, State of Mato Grosso do Sul, Brazil. Rev Bras Reumatol Engl Ed.;57(2):107114.

N-K, J.(2017) Tissue- and cell-specific localization of galectins, $\beta$-galactose-binding animal lectins, and their potential functions in health and disease. Anat Sci Int. 92(1):2536.

R, G., A., V, Y., C, BA. (2012) Glycobiology of immune responses. Ann. N. Y. Acad. Sci. $1253,1-15$.

R, HR., G, L., D, AK., Y, I., D, CP. (2016) Variants in the LGALS9 Gene Are Associated With Development of Liver Disease in Heavy Consumers of Alcohol. Clin Gastroenterol Hepatol;14(5):762-8.e1.

\section{AGRADECIMENTOS}

Capes, PPGIT

ÁREA DE SUBMISSÃO: BIOLOGIA MOLECULAR - BM05 